\title{
The influence of context on word order processing - An fMRI study
}

\author{
Line Burholt Kristensen ${ }^{a, b, *}$, Elisabeth Engberg-Pedersen ${ }^{a}$, \\ Andreas Højlund Nielsen ${ }^{\text {b,c }}$, Mikkel Wallentin ${ }^{\text {b,d }}$ \\ ${ }^{a}$ Department of Scandinavian Studies and Linguistics, University of Copenhagen, Denmark \\ ${ }^{\mathrm{b}}$ Center of Functionally Integrative Neuroscience, Aarhus University Hospital, Denmark \\ ${ }^{\mathrm{c}}$ Department of Anthropology, Archaeology and Linguistics, Aarhus University, Denmark \\ d Center for Semiotics, Aarhus University, Denmark
}

\section{A R T I C L E I N F O}

Article history:

Received 1 March 2011

Received in revised form 7 May 2012

Accepted 17 May 2012

\section{Keywords:}

Syntax

Context

Pragmatics

fMRI

Inferior frontal gyrus

\section{A B S T R A C T}

In languages that have subject-before-object as their canonical word order, e.g. German, English and Danish, behavioral experiments have shown more processing difficulties for object-initial clauses (OCs) than for subject-initial clauses (SCs). For processing of OCs in such languages, neuroimaging experiments have shown more activation in the left inferior frontal gyrus (L-IFG) compared to SCs. The increased activation in L-IFG has been explained in terms of syntactic transformation demands, increased argument hierarchization demands, and increased load on working memory. Behavioral findings have indicated that context may facilitate syntactic processing, but it has not been investigated whether a supportive context can decrease the activity in L-IFG.

With L-IFG as a region of interest (ROI), the present fMRI study of 21 Danish participants investigated how a supportive linguistic context would affect the processing of Danish main clauses with either an initial subject or an initial object. We found more activity in BA 44, BA 45 and BA 47 for OCs compared to SCs. The processing of Danish OCs is thereby seen to elicit effects in L-IFG comparable to previously investigated languages. The context manipulation showed reduced activity in BA 47 for SCs and OCs occurring after a supportive linguistic context, suggesting less pragmatic

\footnotetext{
* Corresponding author. Department of Scandinavian Studies and Linguistics, University of Copenhagen, Njalsgade 120, DK-2300 København S, Denmark.

E-mail addresses: Burholt@hum.ku.dk (L. Burholt Kristensen), eep@hum.ku.dk (E. Engberg-Pedersen), linahn@hum.au.dk (A. Højlund Nielsen), mikkel@cfin.au.dk (M. Wallentin).
} 
processing difficulties for sentence processing in a supportive context. Outside the ROI, the lack of context affected several regions in both the frontal, temporal and parietal lobes.

(c) 2012 Elsevier Ltd. All rights reserved.

\section{Introduction}

A number of behavioral studies have found that object-initial clauses (OCs) are harder to process than subject-initial clauses (SCs) (German: Bader \& Meng, 1999; English: Ferreira, 2003; Finnish: Hyönä \& Hujanen, 1997; Danish: Kristensen, Engberg-Pedersen, \& Poulsen, in review). In accordance with these behavioral results, existing neuroimaging studies have shown more activation in left inferior frontal gyrus (L-IFG) for OCs than for SCs (Ben-Shachar, Palti, \& Grodzinsky, 2004; Bornkessel, Zysset, Friederici, von Cramon, \& Schlesewsky, 2005; Kim et al., 2009). The increased activation in L-IFG has been explained in different terms: as syntactic transformation demands (Ben-Shachar et al., 2004), as increased argument hierarchization demands (Bornkessel et al., 2005) and as increased load on working memory (Fiebach, Schlesewsky, Lohmann, von Cramon, \& Friederici, 2005) for the processing of OCs. However, it has not been investigated whether a supportive linguistic context can decrease the activity in L-IFG.

Within linguistic theories, it is well-established that in some languages OCs can only occur in specific contexts (Kaiser \& Trueswell, 2004; Krifka, 2007; MacWhinney, 1977). For instance, the English object-initial clause beer I like can occur in a contrastive context like I don't drink wine and shots, but beer I like. Psycholinguistic studies have shown that a supportive context can facilitate the processing of OCs when it comes to reading times (for Finnish main clauses: Kaiser \& Trueswell, 2004; for Dutch subordinate clauses: Mak, Vonk, \& Schriefers, 2008; for German main clauses: Weskott, Hörnig, Fanselow, \& Kliegl, 2011), acceptability rating (for German subordinate clauses: Bornkessel \& Schlesewsky, 2006; for German main clauses: Weskott et al., 2011) and comprehension (for Danish main clauses: Kristensen et al., in review). The psycholinguistic finding that context plays a role to the processing of OCs suggests that theories and models of information structure processing should take pragmatic factors into account. Nonetheless, existing neuroimaging studies of OCs have all presented target sentences in isolation, thereby providing sub-optimal conditions for successful processing of the object-initial clauses. Models of sentence processing in the brain that are mainly built on existing neuroimaging studies and that leave contextual factors unnoticed therefore risk being undifferentiated.

Early neuropragmatic studies from the 1980s and up to the 1990s have seen pragmatic processing and the processing of grammar and word order as involving different hemispheres: non-pragmatic language functions were associated with the left hemisphere, while pragmatic language functions (including metaphor comprehension and use of context) were associated with the right hemisphere (Joanette, Goulet, Hannequin, \& Boeglin, 1990). However, recent studies of e.g. metaphoricity have found that pragmatic language processing is not restricted to the right hemisphere and even affects traditional language areas like the L-IFG (Bambini, Gentili, Ricciardi, Bertinetto, \& Pietrini, 2011; Rapp, Leube, Erb, Grodd, \& Kircher, 2004). The psycholinguistic findings that context influences word order processing and the increased awareness that pragmatic processes do not just activate isolated regions in the right hemisphere lead us to question whether the processing of word order in L-IFG can be seen as independent of pragmatic processing, e.g. the integration of context. Adding a pragmatic dimension to neuroimaging studies of word order bears the potential of influencing the way we model language processing in the brain and how we interpret the functions of traditional language areas like the left superior temporal gyrus (L-STG) and the L-IFG. In the present fMRI study, we add a pragmatic dimension to word order processing by presenting target sentences (OCs and SCs) in a linguistic context.

The thought that word order and context go hand in hand is not a new idea to theoretical linguists concerned with information structure, e.g. Krifka (2007) who sees the expression of information 
structure as bound up with common ground. The common ground consists of a set of entities that have been introduced before, and propositions that are presumed to be mutually accepted as shared among the interlocutors (Krifka, 2007). The common ground changes continuously and is taken into consideration every time a speaker utters a sentence. For instance, some information is given and treated as background, while other bits of information are new and will be focused by means of the information structure (word order, morphology or prosody). However, not only the addressee, but also the recipients will attend to what is common ground. There is reason to believe that the common ground between interlocutors is both reflected in the production and the reception of language. Sentence processing is more than bottom-up computation with the recipient building up sentence meaning from syntactic algorithms - EEG-experiments of language processing have shown that the recipient's brain is proactive and can combine code and context on the fly (van Berkum, 2010). Based on what is common ground, heuristics and an understanding of the sender's state of mind, the recipient can make predictions about what is coming up. As for word order processing, the common ground lets recipients know whether a linguistic element has the information structural status that qualifies for fronting to an initial clause position, whereby they will be able to predict the plausibility of an upcoming OC. The concept of common ground is universal, but languages express information structural categories in different ways (Krifka, 2007). The common ground considerations that result in OCs in one language, cannot necessarily explain the occurrence of OCs in another language. In Finnish and Russian, OCs are known to be licensed when the common ground establishes the object as old and the subject as new, but are dispreferred by readers when the object is new (Kaiser \& Trueswell, 2004; Slioussar, 2011). In German, some of the clearest examples of licensing of OCs occur when the common ground has established the object as a contrastive constituent (Bornkessel \& Schlesewsky, 2006; Weskott et al., 2011), as in the previously mentioned example from English I don't drink wine and shots, but beer I like.

The present study examines the influence of context on the processing of Danish SCs and OCs. Danish offers a unique possibility for studying the processing of word order in simple transitive main clauses without inference of morphological markers (Kristensen et al., in review). Like German, Danish is a V2 language, so both subjects and objects can occur clause-initially (followed directly by the finite verb). Only pronominal constituents are marked for case, similar to the English marking of nominative and accusative pronouns (he/him, she/her). The distribution of semantic roles is therefore clear in the following two sentences: the pronoun han is marked for nominative, the pronoun hende is marked for accusative.

Example 1: Pronominal subject in first position

Han inviterede hende til festen.

He invited her to party-the

'He invited her to the party.'

Example 2: Pronominal object in first position

Hende inviterede han til festen

Her invited he to party-the

'Her, he invited to the party.'

However, full NPs are not marked for case, as shown in the following example:

Example 3: Ambiguous sentence with full NPs (i.e. no case-marked pronouns)

Peter inviterede Anne til festen

Peter invited Anne to party-the

a. 'Peter invited Anne to the party.'

b. 'Peter, Anne invited to the party.'

A transitive main clause with two full NP constituents such as the above example is therefore ambiguous between two readings. It can both be interpreted as an SC and as an OC. 
If the sentence contains a complex verb (i.e. a finite verb and a nonfinite verb), the sentence is no longer ambiguous between two readings as shown for nonfinite verbs in example 4 .

Example 4: Unambiguous subject-initial sentence and unambiguous object-initial sentence

a. Peter ville invitere Anne til festen

Peter would invite Anne to party-the

'Peter would invite Anne to the party.'

b. Peter ville Anne invitere til festen

Peter would Anne invite to party-the

'Peter, Anne would invite to the party.'

In the subject-initial version of the above example, the nonfinite verb invitere precedes the second constituent (Anne). In the object-initial version it appears after both constituents. The recipient can therefore use the position of the nonfinite verb as a word order cue to correct distribution of the semantic roles. A recent experiment, however, found that Danish readers miscomprehend OCs more often than SCs, even with the help of word order cues like the position of the nonfinite verb (Kristensen et al., in review). A possible explanation to recipients favoring subject-before-object interpretations over object-before-subject when the clause is presented in isolation, is that recipients' prediction of word order is to some extent based on heuristics (Ferreira, Bailey, \& Ferraro, 2002). Unless the context gives rise to other expectations, recipients have reasons to predict that upcoming sentences have subjectbefore-object structure. One reason for expecting SCs over OCs is that, in Danish, SCs are much more frequent than OCs with a ratio of approximately 1:14 in written Danish transitive main clauses and 3:4 in spoken Danish transitive main clauses (Thomsen, 2008). In a sample of 298 transitive main clauses, excerpted from a corpus of 1899 finite clauses from written and spoken Danish (Thomsen, 2008), the number of OCs (13\% of sampled clauses, i.e. 40 tokens) was smaller than SCs (61\%) and smaller than clauses with neither subject nor object clause-initially (26\%). Most of the OCs contained a fronted pronoun: only 5 out of 40 fronted objects were full NPs. The frequency difference is likely to result in a heuristic preference for SC interpretations over OC interpretations - even when word order cues, as in example 4b, point to an OC interpretation. A second reason for Danish recipients to expect SCs instead of OCs is that OCs in Danish are associated with a limited set of contexts. In Danish, SCs can occur in a wide set of contexts, while OCs are associated with a limited set of functions, notably linking to content of previous clauses, (scalar) focus and contrast (Hansen, 1967; Hansen \& Heltoft, 2011; cf. Harder \& Poulsen, 2001 for an account of differences between the licensing of OCs in Danish and English). Like in German, an explicitly contrastive context appears to facilitate the processing of OCs (Kristensen et al., in review).

In the present fMRI study, we contrasted Danish unambiguous subject-initial main clauses to unambiguous object-initial main clauses. As already mentioned, in Danish the morphology of full NPs is not a cue (unlike in previously investigated languages), since Danish nouns are not inflected for case. But word order can in some cases (i.e. dependent on the placement of nonfinite verbs and sentential adverbs) disambiguate sentences between SC and OC readings. Since there is no one-to-one correspondence between clause-initial position and syntactic role, we could compare the processing of OCs to SCs with word order as the main cue to syntactic role assignment, and without the interference of morphological marking.

Besides comparing OCs to SCs, we examined the effects of reading OCs with or without a preceding supportive textual context. Given that SCs occur in a variety of contexts, while OCs are limited to specific contexts, we assumed that context plays a larger role for successful processing of OCs than for SCs. On top of that, as SCs are more frequent than OCs in Danish, we assumed that readers will have a statistical motivation for expecting sentences to present the subject before the object, unless the context cues them to expect differently. Based on these two assumptions, we predicted that a preceding supportive linguistic context would have a greater facilitating impact on the processing of OCs than SCs, thus resulting in decreased processing costs for OCs.

For the fMRI data, we specifically investigated the role of the L-IFG region, as increased blood oxygen level dependent (BOLD) response in this region has been associated with increased word 
order processing costs (e.g. Christensen \& Wallentin, 2011). We predicted that the processing of OCs would yield a higher BOLD response in L-IFG than SCs, replicating previous studies. For clauses preceded by a supportive context, we expected less activation in L-IFG than for clauses in unsupportive contexts. Finally, we expected an interaction between word order and a supportive context, i.e. a bigger decrease in activation for OCs when in a supportive context than for SCs when in a supportive context. For brain regions outside our ROI, we did not have any specific expectations, as the type of context manipulation employed in this experiment is not obviously comparable to previous neuroimaging tasks.

We expected the response data to resemble the data from Kristensen et al. (in review), a behavioral self-paced reading experiment. The stimuli and the procedure of this behavioral experiment were similar to the present fMRI study (cf. the discussion section for details on the differences). We expected to find less accurate responses and longer RTs to questions following OCs, as the behavioral experiment found such effects. In a preceding supportive context, we expected RTs for both SCs and OCs to be faster, but as the behavioral experiment found no context effect on response accuracy for SCs, we did not expect that for this study either. For both response accuracy and response time, we predicted an interaction between word order and context, as Kristensen et al. (in review) found a stronger facilitating effect of supportive context for OCs than for SCs for these two measures.

\section{Materials and methods}

\subsection{Materials}

The experiment was based on a $2 \times 2$ Latin square design with 2 kinds of word order $(+/-$ objectinitial) and 2 kinds of context ( $+/$ - supportive context). Participants each experienced 30 trials for each of the 4 conditions: SCs (as in Example 5) with an unsupportive linguistic context (Ø-SC), OCs (Example 6 ) with an unsupportive linguistic context (Ø-OC), SCs with a supportive linguistic context (Con-SC) and OCs with a supportive linguistic context (Con-OC). Examples of the stimuli are shown in Table 1. Each of the 120 target sentences in a list were based on a different State of Affairs (SoA), e.g. invite(Peter, Anne). The full stimulus set consisted of $4 \times 120$ trials ( 120 SoAs in $\varnothing-S C, \varnothing-O C$, Con-SC and Con-OC), ensuring that while SoAs were balanced across conditions between participants, each participant never saw the same SoA more than once.

Example 5: Subject-initial target sentence

$\begin{array}{lllll}\text { Peter ville } & \text { dog } & \text { invitere } & \text { Anne } \\ \text { Peter } & \text { would } & \text { however } & \text { invite } & \text { Anne } \\ \text { Subject } & \text { auxiliary verb } & \text { adverb } & \text { main verb } & \text { object } \\ \text { 'Peter would, however, invite Anne.' } & & \end{array}$

Example 6: Object-initial target sentence

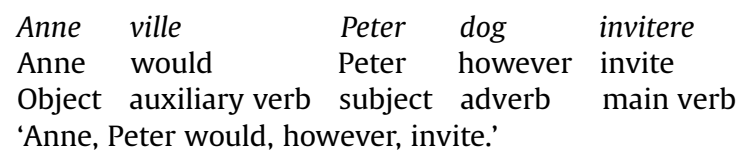

All target sentences comprised the same structural elements: a transitive verb, an auxiliary verb, a subject, an object and the sentential adverb $\operatorname{dog}$ ('however'). SCs and OCs were unambiguous due to word order differences. Clause-initially there is no sequential difference (both have a noun and a finite verb), but the position of the sentential adverb and the main verb disambiguates the two clauses. The sentential adverb $d o g$ was included for two reasons: It supports a contrastive reading as it has a contrastive meaning, and it gives an additional cue to the order of constituents, as dog is placed before the nonfinite verb and therefore placed differently for SCs and OCs. The subject and the object were always human, one 
Table 1

The four conditions (target sentences are underlined).

Ø-SC: unsupportive context + subject-initial target

Denne historie handler om XXX. XXX XXX XXX XXX XXX. Peter ville dog invitere Anne.

This story is about XXX. XXX XXX XXX XXX XXX. Peter would, however, invite Anne.

\section{Con-SC: supportive context + subject-initial target}

Denne historie handler om Peter. De andre drenge brød sig ikke om Anne. Peter ville dog invitere Anne.

This story is about Peter. The other boys did not like Anne. Peter would, however, invite Anne.

\section{Ø-OC: unsupportive context + object-initial target}

Denne historie handler om XXX. XXX XXX XXX XXX XXX. Anne ville Peter dog invitere.

This story is about XXX. XXX XXX XXX XXX XXX. Anne, Peter would, however, invite.

\section{Con-OC: supportive context + object-initial target}

Denne historie handler om Anne. Peter brød sig ikke om de andre piger. Anne ville Peter dog invitere.

This story is about Anne. Peter did not like the other girls. Anne, Peter would, however, invite.

was male, and the other was female. The gender of the agent was balanced across items. All verbs were reversible in order to avoid plausibility effects (Dabrowska \& Street, 2006; Kaiser \& Trueswell, 2004).

Showing sentences in different contexts manipulated the focus of the target sentences. For sentences with an unsupportive context, the context does not contribute cues for resolving the thematic roles of the constituents. However, for the Con-SC and Con-OC conditions, the preceding context contributes to a contrastive reading of the target sentence. In the Con-SC condition of Table 1, the subject (Peter) is contrasted with the other boys. For Con-OC, the object (Anne) is contrasted with the other girls. For Ø-SC and Ø-OC, there are no such contextual cues as the last part of the preceding context is masked by a series of X's.

A fully balanced experimental design would balance the context across trials. In a fully balanced design, the Ø-SC condition could have been left out and replaced by a condition where an SC would occur in an unsupportive context (the context used for Con-OC), and instead of the $\emptyset$-OC, the OC would occur in an unsupportive context (the context used for Con-SC). However, due to the unbalanced distribution of SCs and OCs in Danish, a fully balanced factorial design (with regards to the contexts) was undesirable for this experiment, as it would not allow us to properly investigate the effects of a supportive vs. unsupportive context. This type of design would not be fully balanced in terms of how supportive the contexts were. While OCs in Danish only occur in specific contexts (e.g. the context in Con-OC), OCs are not obligatory in any context, not even after the context in Con-OC. SCs, on the other hand, can occur in more or less all contexts, even the kind of contexts we used for the Con-OC condition. A fully balanced design would create a situation where object-initial reading would be possible (but not obligatory) in a supportive context, and cause a pragmatic violation in an unsupportive context, while a subject-initial reading would be possible for all contexts. A fully balanced factorial design would therefore not allow us to show the effects of a supportive vs. unsupportive context - the main point of the experiment.

Instead of a full factorial design, we therefore used slightly different contexts for the two syntactical conditions and had two unsupportive masked context conditions ( $-\mathrm{SC}$ and $\varnothing-\mathrm{OC}$ ). For the Con-OC condition, we aimed at introducing a context that would establish the object of the target sentence as contrastive, i.e. the context would license an object-initial reading. However, as mentioned, OCs are never obligatory in any context, so the Con-OC context would license an object-initial reading, but a subjectinitial reading would still be possible in the Con-OC context. In the Ø-SC and Ø-OC conditions, part of the text was masked by a series of the letter X. By masking text parts that could establish a contrast, none of the entities of the target sentences would have the information structural status of contrast.

In the Con-SC condition, the initial nominal of the target sentence was contrasted with the subject of the preceding clause, and for Con-OC the initial nominal was contrasted with the object. The context part of the stories never contained object-initial clauses to avoid that structural priming would favor object-initial readings of the target sentences. In principal, SCs thus had a structural priming advantage in our experiment (Pickering \& Ferreira, 2008), but this coincided, as earlier mentioned, with their presumed frequency advantage. 


\subsection{Procedure}

Before entering the scanner, all participants completed a short practice session with five trials that were procedurally similar to, but in terms of content different from, the real experiment.

Stimuli were presented using the Cogent 2000 toolkit (http://www.vislab.ucl.ac.uk/cogent.php) for Matlab (Mathworks Inc., Sherborn, MA, USA). The procedure for stimulus presentation is shown in Fig. 1.

After each target sentence, the participant read a comprehension question of the type Ville Peter invitere Anne? ('Would Peter invite Anne?') and responded by pressing a button using right index finger for "yes", and middle finger for "no" responses. For half of the items, the correct answer was "yes". Response accuracy and response time were logged. Between the different parts of texts (context, target, and task), we inserted time-varying Inter Stimulus Intervals (ISIs) to ensure that the different kinds of events could be separated during the fMRI analysis. After the first 60 trials, the participants had a few minutes break in the scanner before proceeding to the next session. Each session lasted $17 \mathrm{~min}$.

The trials appeared in a pseudorandomized order, i.e. the participants could not predict the word order and the type of context for upcoming trials based on features of the previous trials. At the same time, large clusters of same condition-items were avoided.

Functional MR images were acquired on a General Electrics 3 Tesla system (Milwaukee, WI, USA) with a standard head coil at Aarhus University Hospital. Scans were performed using T*2-weighted gradient echo, echo-planar images (EPI) with BOLD contrast in a sequence with flip angle $=90$, $\mathrm{TR}=2200 \mathrm{~ms}$. For each of the two sessions 460 whole-brain volumes were acquired. Each volume consisted of 40 axial slices (slice thickness $=3.5 \mathrm{~mm}$, FOV $=21.3 \mathrm{~cm}$ ).

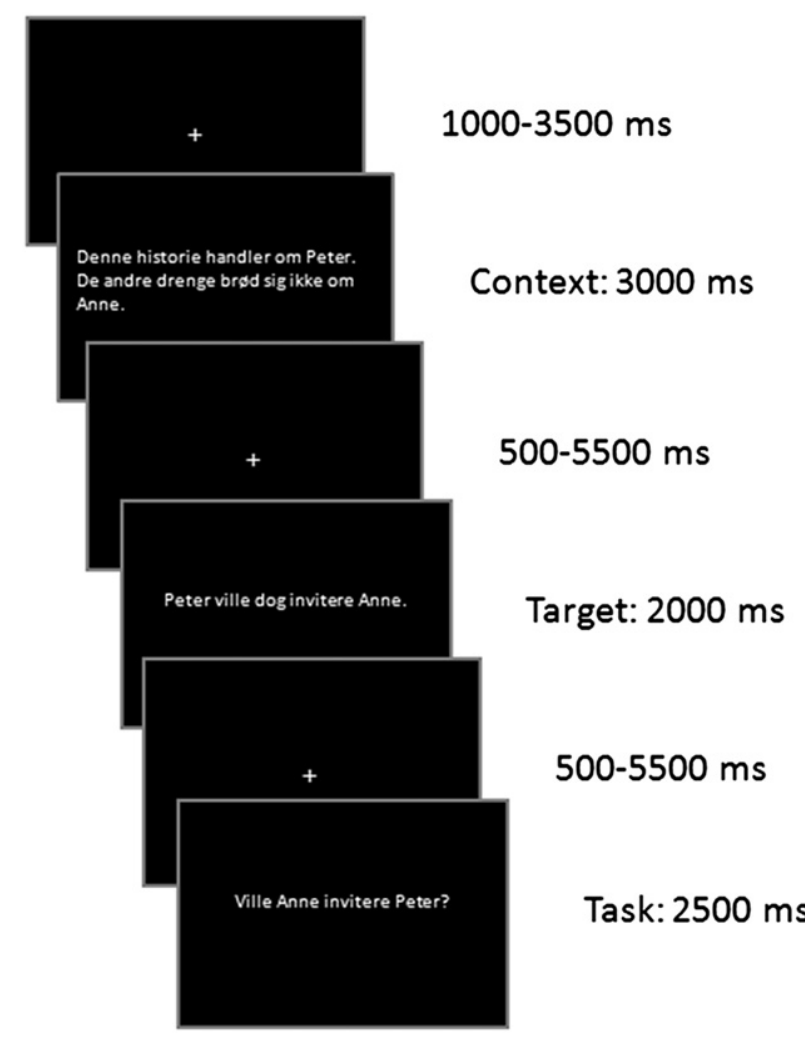

Fig. 1. Procedure for stimuli presentation. 


\subsection{Participants}

24 native speakers of Danish participated in the experiment. All were right-handed and had no medical or mental history or neurological trauma. Participants who gave incorrect responses to more than $1 / 3$ of the comprehension questions for one of the four conditions, were excluded from the data analysis $(n=3$ ), leaving 21 (12 female) participants (mean age $=25$ years, range $=20-36$, standard deviation $=4.5$ ). Gender was not considered important for this experiment (Wallentin, 2009). The experiment was ethically approved by The Central Denmark Region Committees on Biomedical Research Ethics, and participants all gave written consent prior to participation.

\subsection{Data analysis}

The behavioral data was analyzed using mixed-effects models in the statistical software package $\mathrm{R}$ version 2.15.0 (Team, 2010), specifically the lmer function in the lme4 package. Mixed-effects models have the advantages of opting for inclusion of both random effects (e.g. participant) and fixed effects (word order, or any other repeatable factor). A single mixed model can replace traditional by-subjects and by-items ANOVAs and is in addition considered more appropriate than these for analysis of categorical data, such as response accuracy (Jaeger, 2008). The mixed models were fitted to the data. We added random factors one by one to check if they added explanatory power and improved goodness-offit. Only after settling on which variables to include, did we add the two explanatory variables: word order and context. The $p$-values provided for the response time analysis were based on Markov Chain Monte Carlo (MCMC) simulations from the R function pvals.fnc in package LanguageR (Baayen, 2008).

We time-locked the analysis of the imaging data to the display period for the target sentences. The imaging data were analyzed in a two-step general linear model procedure (Worsley \& Friston, 1995) using SPM8 (Statistical Parametric Mapping, Wellcome Department of Imaging Neuroscience, University College London). The imaging data for each participant were motion corrected and realigned to the first EPI image. The images were normalized to the MNI template (Montreal Neurological Institute) using the "normalize" function in SPM and smoothed with an isotropic Gaussian kernel to account for noise and differences between participants (FWHM $10 \times 10 \times 10 \mathrm{~mm}$ ). Single participant effects for each condition were estimated using a general linear model. Low frequency artifacts were filtered out using the SPM8 standard discrete cosine set high-pass filter (128 s cut off) and serial correlation was modeled using an $\operatorname{Ar}(1)$ model. Parameter estimates for target sentences were used in a second level ANOVA analysis to allow for group inferences. ANOVA effects were explored using tcontrasts with a significance threshold of $p<0.05$, family wise error (FWE) corrected for multiple comparisons. Subsequently we performed a region of interest (ROI) analysis for L-IFG.

\section{Results}

\subsection{Behavioral data}

\subsubsection{Response accuracy}

Table 2 shows the percentage of accurate responses. As expected, the difference between accurate answers for SCs (97\% correct) and OCs (90\% correct) was significant ( $p<0.001$ for a mixed model analysis with word order and context as fixed effects, and with participant ID as a random effect).

According to our mixed model analysis (Table 3), there was no significant effect of context, and no significant interaction effect.

Table 2

Percentage of accurate answers across participants.

\begin{tabular}{lcccc}
\hline & $\varnothing-S C$ & Con-SC & $\emptyset-O C$ & Con-OC \\
\hline Correct & $97.1 \%$ & $97.8 \%$ & $88.3 \%$ & $91.1 \%$ \\
Incorrect (wrong or null) & $2.9 \%$ & $2.2 \%$ & $11.7 \%$ & $8.9 \%$ \\
Standard deviation & 1.11 & .73 & 2.56 & 1.93 \\
\hline
\end{tabular}


Table 3

Mixed model for response accuracy across participants.

\begin{tabular}{|c|c|c|c|c|}
\hline \multicolumn{5}{|l|}{ Random effects } \\
\hline Groups & Name & \multicolumn{2}{|c|}{ Variance } & Std. dev. \\
\hline $\begin{array}{ll}\text { Subject } & \text { Int } \\
\text { Number of observations: } 2520 . \text { Numbe }\end{array}$ & Ips: subject & \multicolumn{2}{|c|}{.3889} & .6236 \\
\hline \multicolumn{5}{|l|}{ Fixed effects } \\
\hline & Estimate & Std. error & $z$ Value & $\operatorname{Pr}(>|z|)$ \\
\hline (Intercept) & -3.6980 & .2797 & -13.219 & $<2 \mathrm{e}-16^{* * *}$ \\
\hline Context (supportive) & -.2600 & .3651 & -.712 & .476 \\
\hline Word order (object-initial) & 1.5403 & .2727 & 5.647 & $1.64 \mathrm{e}-08^{* * *}$ \\
\hline $\begin{array}{l}\text { Interaction of context and word order } \\
\text { (supportive and object-initial) }\end{array}$ & -.0605 & .4115 & -.147 & .883 \\
\hline
\end{tabular}

Significant codes: (***) .001 ; $^{\text {(*) }} .01$; $^{\text {‘*’ }} .05$.

\subsubsection{Response time}

We only examined the RT for correct answers (Table 4). RTs were logarithmically transformed before the analysis.

Trial number and the expected answer to the comprehension question (yes or no) both had an impact on RT, and we therefore included these two variables as a fixed effects in our mixed model analysis of RT along with word order and context, and with participant as a random effect. RTs that were 2.5 standard deviations from the mean were considered outliers. We refitted the model after removing the outliers (44 outliers, $2 \%$ of observations).

According to ANOVA based on our model (Table 5), participants responded faster with time $(p<0.0001)$ and participants responded more slowly when responding no $(p<0.0001)$. Word order did not have a significant effect on RT (though marginally significant: $p>0.07$ ), but context did: responses were faster to sentences with a supportive context $(p<0.05)$. There was no significant interaction.

Table 4

Mean response time for correct answers (outliers excluded).

\begin{tabular}{lllll}
\hline & $\emptyset$-SC & Con-SC & $\emptyset$-OC & Con-OC \\
\hline Reaction time $(\mathrm{ms})$ & 1295.6 & 1231.2 & 1317.3 & 1243.1 \\
\hline
\end{tabular}

Table 5

Mixed model for logarithmically transformed response times (outliers excluded).

\begin{tabular}{|c|c|c|c|c|}
\hline \multicolumn{5}{|l|}{ Random effects } \\
\hline Groups & Name & \multicolumn{2}{|c|}{ Variance } & Std. dev. \\
\hline Subject & (Intercept) & \multicolumn{2}{|c|}{.02794} & .1671 \\
\hline Residual & & .088 & & .2981 \\
\hline \multicolumn{5}{|c|}{ Number of observations: 2314. Number of groups: subject, 21} \\
\hline \multicolumn{5}{|l|}{ Fixed Effects } \\
\hline & Estimate & Std. error & $t$ Value & $p(\mathrm{MCMC})$ \\
\hline (Intercept) & 7.3534 & .0405 & 181.46 & $.0001^{* * *}$ \\
\hline Trial no. & -.0039 & .0002 & -21.38 & $.0001^{* * *}$ \\
\hline Expected answer (yes) & -.1267 & .0124 & -10.21 & $.0001 * * *$ \\
\hline Context (supportive) & -.0338 & .0172 & -1.97 & $.0466^{*}$ \\
\hline Word order (object-initial) & .0324 & .0177 & 1.83 & .0694 \\
\hline $\begin{array}{l}\text { Interaction of context and word order } \\
\text { (supportive and object-initial) }\end{array}$ & -.0148 & .0248 & -.60 & .5512 \\
\hline
\end{tabular}

Significant codes: ‘***' .001 ; $^{\text {(**’ }} .01 ;{ }^{\text {‘*’ }} .05$. 


\subsection{Neuroimaging results}

\subsubsection{Whole-brain results}

A whole-brain analysis (Fig. 2) showed a main effect of word order both when subtracting subjectinitial conditions from object-initial conditions and when doing the opposite subtraction. Object-initial conditions showed increased BOLD responses in a number of areas, most significantly in the left frontal and the left temporal lobe (Table 6). For subject-initial conditions, we found a few small areas with increased activation in both hemispheres (Table 7).

We also found a main effect of context (by subtracting sentences with a supportive context from sentences with an unsupportive context - see Table 8), particularly in the left frontal and left temporal lobes. However, we found no interaction effect of word order and context for the whole-brain analysis, i.e. a supportive context did not have a more facilitating effect for OCs than for SCs.

Table 6

Main effect of initial object (FWE $p>0.05$ ).

\begin{tabular}{|c|c|c|c|c|c|c|c|}
\hline Hemisphere & Lobe & Label & Size & Z score & Local $\max (\mathrm{x})$ & Local max(y) & Local $\max (\mathrm{z})$ \\
\hline Left & Frontal lobe & Superior frontal gyrus & 727 & 6.20 & -6 & 10 & 58 \\
\hline Left & Frontal lobe & Precentral gyrus & 648 & 5.80 & -54 & 14 & 10 \\
\hline Left & Frontal lobe & Middle frontal gyrus & 642 & 6.68 & -38 & -2 & 58 \\
\hline Right & Frontal lobe & Precentral gyrus & 56 & 4.76 & 10 & 8 & 2 \\
\hline Right & Frontal lobe & Inferior frontal gyrus & 45 & 4.77 & 32 & 22 & -2 \\
\hline Left & Temporal lobe & Middle temporal gyrus & 791 & 5.78 & -52 & -50 & 4 \\
\hline Left & Parietal lobe & Superior parietal lobule & 136 & 5.10 & -28 & -60 & 46 \\
\hline Left & Parietal lobe & Superior parietal lobule & 8 & 4.60 & -14 & -68 & 56 \\
\hline Left & Sub-lobar & Thalamus & 185 & 5.21 & -14 & -10 & 6 \\
\hline Left & Sub-lobar & Caudate & 47 & 4.83 & -10 & 10 & 4 \\
\hline
\end{tabular}

Table 7

Main effect of initial subject (FWE $p>0.05$ ).

\begin{tabular}{|c|c|c|c|c|c|c|c|}
\hline Hemisphere & Lobe & Label & Size & $Z$ score & Local max $(x)$ & Local max $(y)$ & Local max $(z)$ \\
\hline Right & Frontal lobe & Medial frontal gyrus & 1 & 4.60 & 32 & -12 & 16 \\
\hline Left & Sub-lobar & Extra-nuclear & 20 & 4.89 & -44 & 12 & 2 \\
\hline Left & Cerebellum anterior lobe & Culmen & 3 & 4.66 & -44 & 2 & -6 \\
\hline
\end{tabular}

Table 8

Main effect of unsupportive context (FWE $p>0.05$ ).

\begin{tabular}{lllccccc}
\hline Hemisphere & Lobe & Label & Size & $Z$ score & Local max $(x)$ & Local max $(y)$ & Local max $(z)$ \\
\hline Left & Frontal lobe & Middle frontal gyrus & 622 & 6.55 & -42 & 16 & 50 \\
Left & Frontal lobe & Superior frontal gyrus & 395 & 6.39 & -10 & 26 & 66 \\
Left & Frontal lobe & Inferior frontal gyrus & 253 & 5.71 & -46 & 36 & -8 \\
Right & Frontal lobe & Inferior frontal gyrus & 184 & 5.56 & 50 & 30 & -8 \\
Left & Temporal lobe & Superior temporal gyrus & 1170 & 6.48 & -46 & -60 & 26 \\
Left & Temporal lobe & Middle temporal gyrus & 782 & 6.21 & -58 & -44 & -4 \\
Left & Temporal lobe & Inferior temporal gyrus & 292 & 6.11 & -52 & -2 & -34 \\
Right & Temporal lobe & Middle temporal gyrus & 225 & 5.36 & 48 & 6 & -36 \\
Middle & Parietal lobe & Precuneus & 358 & 5.56 & 0 & -58 & 38 \\
Right & Parietal lobe & Angular gyrus & 266 & 5.64 & 54 & -62 & 34 \\
\hline
\end{tabular}




\subsubsection{Region of interest: left inferior frontal gyrus}

We defined our region of interest (ROI) as comprising left BA 44, BA 45 and BA 47, based on the Wake Forest University Pickatlas. BA 44 and 45 were activated in previous word order experiments (Ben-Shachar et al., 2004; Bornkessel et al., 2005; Christensen \& Wallentin, 2011), as well as during processing of non-rigid versus rigid order of non-linguistic symbols (Tettamanti et al., 2009). BA 47 is also seen as central to the left frontal language network (Hagoort, 2005; Hagoort, Hald, Bastiaansen, \& Petersson, 2004).

When subtracting object-initial conditions with subject-initial ones, left BA 44, left BA 45 and left BA 47 all showed increased activation. BA 47 was found to be additionally affected by context (i.e. exhibiting greater activation in the unsupportive context conditions (Ø-OC and Ø-SC) than in the supportive contexts (Con-OC and Con-SC)), see Fig. 3.

We found no interaction effects in our ROI, i.e. supportive contexts did not decrease activity more for OCs than for SCs.

\section{Discussion}

Our experiment had as its aims to examine the processing of clauses with different word order in Danish and to examine the influence of a preceding linguistic context on sentence processing.

\subsection{Word order}

We investigated the role of L-IFG in processing Danish main clauses with two different kinds of word order. As Danish nouns are not case-marked, it is possible to investigate how language users deal with main clauses for which no case-marking is provided (unlike e.g. German), for which word order is relatively flexible (compared to e.g. English), and thus for which word order is the main cue to mapping the syntactic roles. In alignment with results from previous studies (Hebrew: Ben-Shachar et al., 2004; German: Bornkessel et al., 2005; Japanese: Kim et al., 2009), we found increased activation in L-IFG for OCs compared to SCs. Thus our results from Danish add support to theories claiming that L-IFG plays a role in word order processing across languages, particularly since word order is the main cue to mapping the syntactic roles in our material. We also find support for claims that OCs increase activity in L-IFG.

The effects of object fronting are also reflected in the response accuracy data. Responses to OCs were significantly less accurate than to SCs. The lower accuracy for OCs is in line with previous behavioral experiments on off-line assessment of clauses (grammaticality judgment: Bader \& Meng, 1999; response accuracy: Bornkessel, Schlesewsky, \& Friederici, 2003; Ferreira, 2003), and thereby in line with general findings that OCs increase processing costs (e.g. increased word-by-word reading times: Hyönä \& Hujanen, 1997).

We did not find a significant effect of object fronting for the RTs of correct answers although previous experiments find that responses to OCs in other languages are slower (Bornkessel et al., 2003; Ferreira, 2003; also for Danish: Kristensen et al., in review). A possible explanation for the lack of an effect of word order on RT may be that the time-varying ISIs between the target sentence and the question task in our experiment neutralized a possible RT effect as the participants had time to think about the target sentence before responding.

Altogether, our experiment is in line with previous research that shows a higher processing cost for OCs, and that localizes a good proportion of the processing activity to L-IFG. However, it is still a debated issue why OCs are more difficult and what the precise function of L-IFG is: Fiebach et al. (2005), Ben-Shachar et al. (2004) and Bornkessel et al. (2005) each give different explanations for increased L-IFG activity during processing of OCs.

Fiebach et al. (2005) put forth the idea that OCs increase the syntactic working memory load. Using fMRI, they examined the processing of object-initial and subject-initial subordinate clauses in German indirect wh-questions. Activation increased in BA 44 of L-IFG for OCs compared to SCs, but only if the object was relatively far away from its canonical position. They conclude that L-IFG activity is not as much related to syntactic complexity (dislocated object versus dislocated subject) as to working memory demands (long distance versus short distance dislocation). Supporting this, Wallentin and co- 
workers found that L-IFG was modulated by working memory performance during language processing in the absence of a syntactical contrast (Wallentin, Roepstorff, Glover, \& Burgess, 2006). Our results are consistent with a working memory hypothesis, but do not directly test this assumption.

Ben-Shachar et al. (2004) see L-IFG activity for Hebrew OCs as essentially related to syntactic movement. For processing of Hebrew main clauses, Ben-Shachar et al. (2004) found more activation for OCs than for SCs in L-IFG, ventral precentral sulcus and bilateral posterior superior temporal sulcus. Ben-Shachar et al. (2004) conclude that the increased activation reflects transformation processes.

Bornkessel et al. (2005) suggests that the difference between processing OCs and SCs in German is a difference in what they call argument hierarchization demands. In the Actor-Undergoer Hierarchy (Van Valin \& LaPolla, 1997), there are two kinds of semantic macro-roles: the generalized agent-type role called Actor is hierarchically superior to the generalized patient-type role labeled Undergoer. Bornkessel et al. (2005) assume that the argument hierarchization demands increase if the Undergoer occurs before the Actor, as in most object-initial sentences. In their study of German embedded clauses, Bornkessel and colleagues compared the processing of Actor-before-Undergoer to Undergoer-beforeActor. In our present study, the SCs all have Actor-before-Undergoer structure, and the OCs all have Undergoer-before-Actor structure. Besides comparing SCs and OCs with such semantic macro-role structures, Bornkessel et al. (2005) used specific German transitive verbs like auffallen (English 'attract attention') to create SCs with Undergoer-before-Actor structure and OCs with Actor-beforeUndergoer structure. In the case of verbs like auffallen, the argument hierarchization demands are therefore higher for SCs than for OCs. They found that increased argument hierarchization demands activate a main network of left inferior frontal, left ventral premotor, left posterior superior temporal and bilateral parietal regions. While the posterior superior temporal sulcus was sensitive to the degree of morphological informativeness of the arguments, the L-IFG was a function of argument linearization parameters. Comparing their findings to those of Ben-Shachar et al. (2004) and Röder, Stock, Neville, Bien, and Rösler (2002), Bornkessel et al. (2005) suggest that the frontotemporal network engaged in the processing of argument hierarchies is essentially similar across languages.

In a recent study, Christensen and Wallentin (2011) also found L-IFG effects in an experiment investigating alternative constructions known as the Locative Alternation (Pinker, 1989) using Danish as target language. Interestingly, semantic anomaly effects arising from the processing of semantically incongruent locative constructions, were found in exactly the same parts of L-IFG as the effect of constructional alternations (affecting argument hierarchization), suggesting that L-IFG response may be related to a general linguistic processing cost tapping mechanism.

Same as previous sentence processing studies in a number of languages, the fronting effect in our fMRI data supports the role of L-IFG, particularly BA 44/45, in word order processing, but replicating this effect for Danish main clauses does not support one explanation over the other (increased working memory load (Fiebach et al., 2005), syntactic transformation demands (Ben-Shachar et al., 2004) or increased argument hierarchization demands (Bornkessel et al., 2005)).

\subsection{Context}

The second aim of our study was to investigate the role of context on sentence processing. For languages with basic subject-before-object word order, it is well-established that pragmatics is an integral part of processing OCs (Krifka, 2007; MacWhinney, 1977; Vallduví, 1993), and for e.g. Finnish it is empirically supported by a self-paced reading study of Finnish main clauses (Kaiser \& Trueswell, 2004). The Finnish participants read clauses that were either preceded by a supportive or an unsupportive context. Their reading times showed that supportive contexts had a greater facilitation effect for Finnish OCs than for SCs. However, neither Bornkessel et al. (2005), nor Ben-Shachar et al. (2004), nor Fiebach et al. (2005) mention the role of context when explaining their results. Digging into the influence of context on sentence processing is one way of seeking support for one theory over the other. According to a transformational approach like that of Ben-Shachar et al. (2004) and Kim et al. (2009), the increased activity in L-IFG for OCs reflects syntactic transformation. Neither of these studies addresses possible effects of frequency of structures and lack of context in the discussion of their results. While Kim et al. (2009) mention that frequency and contextual support has played a role in Kaiser and Trueswell's (2004) behavioral study, they see complexity of sentence structure as the main 


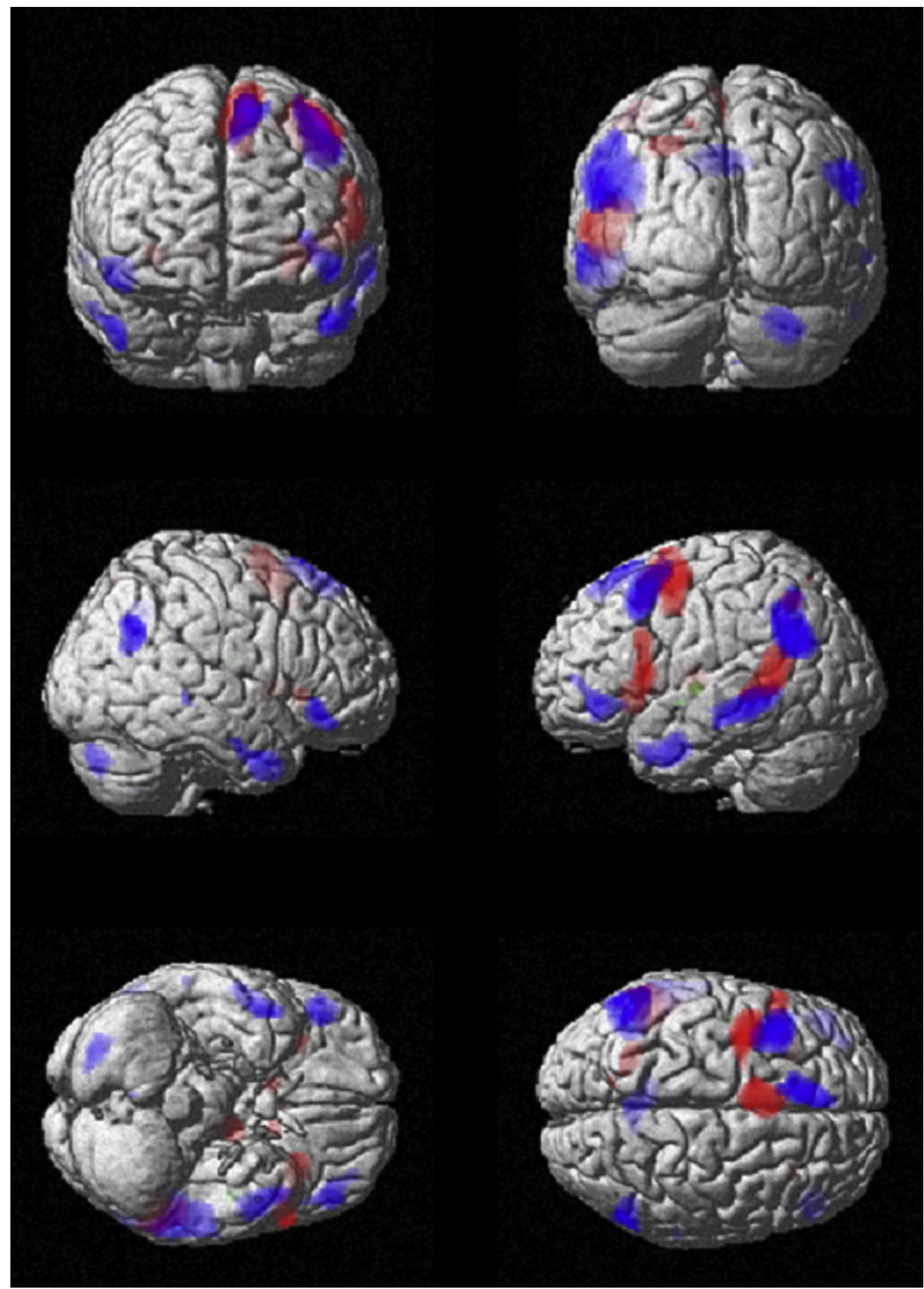

Fig. 2. Whole-brain results. The figure shows the main effect of initial object in red, the main effect of initial subject in green and the main effect of an unsupportive context (FWE $p>0.05$ ) in blue. (For interpretation of the references to color in this figure legend, the reader is referred to the web version of this article.) 


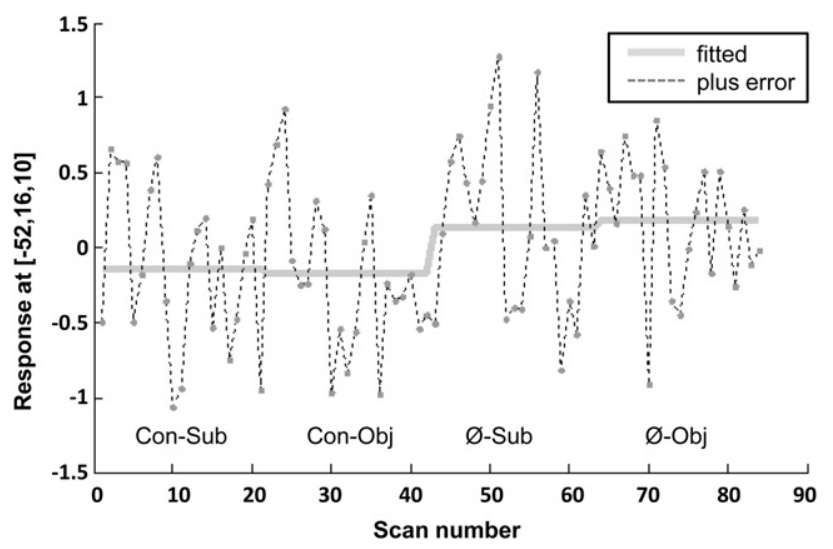

Fig. 3. Fitted responses for ROI, main effect of context.

factor for OC difficulties, and they explain the increased BOLD response in L-IFG as caused by syntactic movement only. Being the main factor, we assume that Ben-Shachar et al. (2004) and Kim et al. (2009) see the proposed effect of syntactic movement on the BOLD response in L-IFG as being stable across context, i.e. it should not change with the introduction of a supportive context, as seen in the present experiment. If context would have a greater facilitating effect on object-initial than on subject-initial sentence processing (resulting in decreased L-IFG activity), it would pose an even greater challenge to explanations based on syntactic transformation. Behavioral experiments (Kaiser \& Trueswell, 2004; Kristensen et al., in review) show such a facilitating effect of a supportive context. However, the effect has not yet been linked to activity in L-IFG, i.e. the interaction effect of behavioral measures has not yet been found with respect to L-IFG activity. Still, given that all contexts in our study were SCs, a contextual effect consisting solely of structural priming should favor processing of SCs. The fact that such an effect was not observed either, we speculate, may be due to two different effects affecting the two sentence types: a structural priming effect for SCs and a facilitation effect for OCs. Further experiments are needed to substantiate these claims.

As mentioned earlier, we did a self-paced reading experiment (Kristensen et al., in review) prior to our fMRI study. For the reading experiment, we tested 32 participants using the same $2 \times 2$ design as for this fMRI study. Unlike the present fMRI study, for which we did not find any interaction effects, our self-paced reading experiment showed an interaction effect for both response accuracy and response time, showing that a supportive context was more helpful to OCs than SCs. The lack of interaction effects in the present experiment leads us to conclude that the supportive contexts were not as helpful in the fMRI setting as in the behavioral experiment. There may be a number of reasons why the behavioral results of the two experiments were different from each other. For instance, the behavioral experiment was shorter than the fMRI experiment, and it included a number of fillers (intransitive sentences), and these differences may have influenced reading strategies and response strategies in ways we cannot clearly predict. To us, the most plausible explanation to finding interaction effects in only one of the two experiments, is the difference in length of ISI. The behavioral experiment was selfpaced, and therefore did not have long ISIs between the different parts of the text. The fMRI study, on the other hand, had long ISIs, which allowed us to better separate the different events in our neuroimaging analysis. It is possible that the long ISIs between context and target sentence made it difficult for the participants to integrate the target sentence with the context. Thus, the participants did not get the full advantage of the contextual aid in our fMRI study. As for neuroimaging results, we did see decreased activation of L-IFG for Con-OC and Con-SC conditions, indicating that a supportive context does influence the sentence processing, but there was no interaction effect. However, since the behavioral measures of our fMRI study did not show any interaction effects either, we should not reject the idea that an interaction effect in L-IFG would be possible under other circumstances. 
The contextual aid is only reflected in a general decrease in RT and in decreased BOLD response in BA 47. It is not surprising to see a BA 47 decrease for the supportive context conditions, as this region is seen activated for pragmatically incongruent conditions (Hagoort et al., 2004; Tesink et al., 2009) and for context integration during metaphor comprehension (Bambini et al., 2011; Rapp et al., 2004), i.e. our data support a pragmatic processing function of BA 47.

\section{Conclusion}

As expected, we found evidence that the processing of object-initial clauses yields higher BOLD response in L-IFG than subject-initial clauses, and we saw less activation in some parts of L-IFG (BA 47) for sentences preceded by a supportive context. However, we cannot reject the null-hypothesis when it comes to finding an interaction between OCs and a supportive context. Nevertheless, this does not mean that the hypothesis should be rejected for future research, as factors such as long ISIs and the lack of fillers may well have led the participants to focus more on comprehending the target sentences in isolation than on integrating target sentences with the previous context.

It is still relevant to investigate whether a supportive context decreases activation in L-IFG for OCs to a greater extent than for SCs. Theories of syntactic transformation as proposed by Ben-Shachar et al. (2004) and Kim et al. (2009) appear to be based on the premise that syntactic transformations occur regardless of non-syntactic circumstances. Thus if a preceding context results not only in interaction effects for behavioral measures such as comprehension accuracy and response time, but also for the level of BOLD response in L-IFG, it would pose a challenge to theories that link activation of L-IFG to syntactic transformation.

A further investigation of the role of context on neural activation of L-IFG is relevant to both theoretical linguistics and to human brain mapping. Results may serve as input in theoretical linguistics discussions of sentence analysis and word order, and for neuroscience they may contribute to a more multifaceted understanding of the role of L-IFG in language processing.

\section{Acknowledgments}

This research was supported by the Faculty of Arts, University of Copenhagen, by Center of Functionally Integrative Neuroscience, Aarhus University, and by The MindLab Grant from the Danish Ministry of Science, Technology and Innovation.

\section{References}

Baayen, R. H. (2008). Analyzing linguistic data. A practical introduction to statistics using R. Cambridge: Cambridge University Press.

Bader, M., \& Meng, M. (1999). Subject-object ambiguities in German embedded clauses: an across-the-board comparison. Journal of Psycholinguistic Research, 28, 121-143.

Bambini, V., Gentili, C., Ricciardi, E., Bertinetto, P. M., \& Pietrini, P. (2011). Decomposing metaphor processing at the cognitive and neural level through functional magnetic resonance imaging. Brain Research Bulletin, 86, 203-216.

Ben-Shachar, M., Palti, D., \& Grodzinsky, Y. (2004). Neural correlates of syntactic movement: converging evidence from two fMRI experiments. Neurolmage, 21, 1320-1336.

Bornkessel, I., \& Schlesewsky, M. (2006). The role of contrast in the local licensing of scrambling in German: evidence from online comprehension. Journal of Germanic Linguistics, 18, 1-43.

Bornkessel, I., Schlesewsky, M., \& Friederici, A. D. (2003). Eliciting thematic reanalysis effects: the role of syntax-independent information during parsing. Language and Cognitive Processes, 18, 269-298.

Bornkessel, I., Zysset, S., Friederici, A. D., von Cramon, D. Y., \& Schlesewsky, M. (2005). Who did what to whom? The neural basis of argument hierarchies during language comprehension. Neurolmage, 26, 221-233.

Christensen, K. R., \& Wallentin, M. (2011). The locative alternation: distinguishing linguistic processing cost from error signals in Broca's region. NeuroImage, 56, 1622-1631.

Dabrowska, E., \& Street, J. (2006). Individual differences in language attainment: comprehension of passive sentences by native and non-native English speakers. Language Sciences, 28, 604-615.

Ferreira, F. (2003). The misinterpretation of noncanonical sentences. Cognitive Psychology, 47, 164-203.

Ferreira, F., Bailey, K. G. D., \& Ferraro, V. (2002). Good-enough representations in language comprehension. Current Directions in Psychological Science (Wiley-Blackwell), 11, 11.

Fiebach, C. J., Schlesewsky, M., Lohmann, G., von Cramon, D. Y., \& Friederici, A. D. (2005). Revisiting the role of Broca's area in sentence processing: syntactic integration versus syntactic working memory. Human Brain Mapping, 24, 79-91.

Hagoort, P. (2005). On Broca, brain, and binding: a new framework. Trends in Cognitive Sciences, 9, 416-423. 
Hagoort, P., Hald, L., Bastiaansen, M., \& Petersson, K. M. (2004). Integration of word meaning and world knowledge in language comprehension. Science, 304, 438-441.

Hansen, A. (1967). Moderne dansk, Vol. 1. Copenhagen: Det Danske Sprog- og Litteraturselskab Grafisk Forlag.

Hansen, E., \& Heltoft, L. (2011). Grammatik over det Danske Sprog. Det Danske Sprog- og Litteraturselskab.

Harder, P., \& Poulsen, S. (2001). Editing for speaking: first position, foregrounding and object fronting in Danish and English. In Ikonicitet og Struktur (pp. 1-22). Netværk for Funktionel Lingvistik, Engelsk Insititut, Københavns Universitet.

Hyönä, J., \& Hujanen, H. (1997). Effect of word order and case marking on sentence processing in Finnish: an eye fixation analysis. Quarterly Journal of Experimental Psychology, 50A, 841-858.

Jaeger, T. F. (2008). Categorical data analysis: away from ANOVAs (transformation or not) and towards logit mixed models. Journal of Memory and Language, 59, 434-446.

Joanette, Y., Goulet, P., Hannequin, D., \& Boeglin, J. (1990). Right hemisphere and verbal communication. New York, NY, US: Springer-Verlag Publishing.

Kaiser, E., \& Trueswell, J. C. (2004). The role of discourse context in the processing of a flexible word-order language. Cognition, 94, 113-147.

Kim, J., Koizumi, M., Ikuta, N., Fukumitsu, Y., Kimura, N., Iwata, K., et al. (2009). Scrambling effects on the processing of Japanese sentences: an fMRI study. Journal of Neurolinguistics, 22, 151-166.

Krifka, M. (2007). Basic notions of information structure. In C. Féry, G. Fanselow, \& M. Krifka (Eds.), Working papers of the SFB632, Interdisciplinary studies on information structure (ISIS), Vol. 6 (pp. 13-56). Potsdam: Universitätsverlag Potsdam.

Kristensen, L. B., Engberg-Pedersen, E., \& Poulsen, M. Context improves comprehension of fronted objects, in review.

MacWhinney, B. (1977). Starting points. Language, 53, 152-168.

Mak, W., Vonk, W., \& Schriefers, H. (2008). Discourse structure and relative clause processing. Memory E Cognition, 36, $170-181$.

Pickering, M. J., \& Ferreira, V. S. (2008). Structural priming: a critical review. Psychological Bulletin, 134, 427-459.

Pinker, S. (1989). Learnability and cognition: The acquisition of argument structure. Cambridge, MA, US: The MIT Press.

Röder, B., Stock, O., Neville, H., Bien, S., \& Rösler, F. (2002). Brain activation modulated by the comprehension of normal and pseudo-word sentences of different processing demands: a functional magnetic resonance imaging study. NeuroImage, 15, 1003-1014.

Rapp, A. M., Leube, D. T., Erb, M., Grodd, W., \& Kircher, T. T. J. (2004). Neural correlates of metaphor processing. Cognitive Brain Research, 20, 395-402.

Slioussar, N. (2011). Processing of a free word order language: the role of syntax and context. Journal of Psycholinguistic Research, 40, 291-306.

Team, R. D. C. (2010). In R. F. f. S. Computing. (Ed.), R: A language and environment for statistical computing, Vienna, Austria.

Tesink, C. M. J. Y., Petersson, K. M., van Berkum, J. J. A., van den Brink, D. L., Buitelaar, J. K., \& Hagoort, P. (2009). Unification of speaker and meaning in language comprehension: an fMRI study. Journal of Cognitive Neuroscience, 21, 2085-2099.

Tettamanti, M., Rotondi, I., Perani, D., Scotti, G., Fazio, F., Cappa, S. F., et al. (2009). Syntax without language: neurobiological evidence for cross-domain syntactic computations. Cortex, 45, 825-838.

Thomsen, D. B. (2008). OVS i dansk. In Written assignment for the course "Lingvistiske Metoder". University of Copenhagen.

Vallduví, E. (1993). The informational component. Philadelphia: University of Pennsylvania.

van Berkum, J. (2010). The brain is a prediction machine that cares about good and bad - any implication for neuropragmatics? Italian Journal of Linguistics, 22, 181-208.

Van Valin, R. D., \& LaPolla, R. J. (1997). Syntax. Structure, meaning and function. Cambridge: University Press.

Wallentin, M. (2009). Putative sex differences in verbal abilities and language cortex: a critical review. Brain and Language, 108, 175-183.

Wallentin, M., Roepstorff, A., Glover, R., \& Burgess, N. (2006). Parallel memory systems for talking about location and age in precuneus, caudate and Broca's region. Neurolmage, 32, 1850-1864.

Weskott, T., Hörnig, R., Fanselow, G., \& Kliegl, R. (2011). Contextual licensing of marked OVS word order in German. Linguistische Berichte, 2011, 3-18.

Worsley, K. J., \& Friston, K. J. (1995). Analysis of fMRI time-series revisited-again. NeuroImage, 2, 173-181. 